\title{
High serum bicarbonate level within the normal range prevents the progression of chronic kidney disease in elderly chronic kidney disease patients
}

\author{
Eiichiro Kanda ${ }^{1,2^{*}}$, Masumi $\mathrm{Ai}^{2}$, Masayuki Yoshida ${ }^{2}$, Renjiro Kuriyama ${ }^{3}$ and Tatsuo Shiigai ${ }^{4}$
}

\begin{abstract}
Background: Metabolic acidosis leads to chronic kidney disease (CKD) progression. The guidelines recommend a lower limit of serum bicarbonate level, but no upper limit. For serum bicarbonate level to be clinically useful as a therapeutic target marker, it is necessary to investigate the target serum bicarbonate level within the normal range to prevent CKD progression.
\end{abstract}

Methods: One hundred and thirteen elderly CKD patients, whose serum bicarbonate level was controlled within the normal range, were enrolled in this retrospective cohort study in Ibaraki, Japan. Outcome was defined as a decrease of $25 \%$ or more in estimated glomerular filtration rate (eGFR) or starting dialysis. We used Cox proportional hazard models adjusted for patients' characteristics to examine the association between serum bicarbonate level and the outcome.

Results: Female patients were 36.3\%: average age (SD), 70.4 (6.6) years; eGFR, 25.7 (13.6) $\mathrm{ml} / \mathrm{min} / 1.73 \mathrm{~m}^{2}$; serum bicarbonate level, 27.4 (3.2) mEq/l. Patients with the lowest quartile of serum bicarbonate levels [23.4 (1.8) mEq/l] showed a high risk of CKD progression compared with patients with high serum bicarbonate levels [28.8 (2.3) mEq/ I]: adjusted hazard ratio (HR), 3.511 (95\% Cl, 1.342-9.186). A $1 \mathrm{mEq} / \mathrm{l}$ increase in serum bicarbonate level was associated with a low risk of CKD progression: adjusted HR, 0.791 [95\% confidence interval (Cl), 0.684-0.914].

Conclusions: In elderly CKD patients, our findings suggest that serum bicarbonate level is independently associated with CKD progression, and that a high serum bicarbonate level is associated with a low risk of CKD progression. A high target serum bicarbonate level within the normal range may be effective for preventing CKD progression.

Keywords: Bicarbonate, CKD, Elderly, CKD progression, Acidosis

\section{Background}

As the number of functioning nephrons decreases in chronic kidney disease (CKD), total ammonium excretion level begins to decrease when glomerular filtration rate (GFR) is below 40 to $50 \mathrm{~mL} / \mathrm{min} / 1.73 \mathrm{~m}^{2}[1,2]$. This results in net retention of hydrogen ions and metabolic acidosis [1,2]. Metabolic acidosis leads to CKD progression [3]. There is some evidence of the relationship between serum bicarbonate level and CKD progression. Observational studies showed an association between a

\footnotetext{
* Correspondence: tokyo.kyosai.kanda@gmail.com

'Department of Nephrology, Tokyo Kyosai Hospital, Nakameguro 2-3-8,

Meguroku, Tokyo 153-8934, Japan

${ }^{2}$ Tokyo Medical and Dental University, Bioethics Research Center, Yushima

1-5-45, Bunkyoku, Tokyo113-8519, Japan

Full list of author information is available at the end of the article
}

low serum bicarbonate level and progression of kidney diseases [4-7]. Intervention studies show that bicarbonate supplementation slowed the progression of kidney diseases [8-12].

Kidney function declines with histological changes of the kidney with aging $[13,14]$. United States National Health and Nutrition Examination Surveys showed that a decreased GFR is associated with a high prevalence of acidosis in elderly CKD patients [15]. Although elderly CKD patients have a high risk of metabolic acidosis, we were unable to find any reports about the effect of serum bicarbonate level on CKD progression in elderly CKD patients.

At present, the National Kidney Foundation Kidney Disease Outcomes Quality Initiative (K/DOQI) guidelines 
2000 and the Care of Australians with Renal Impairment (CARI) guidelines recommend that serum bicarbonate level should be maintained at or above $22 \mathrm{mEq} / \mathrm{l}[16,17]$. However, the guidelines recommend only this lower limit of the target serum bicarbonate level, but no upper limit in non-dialysis-dependent CKD patients. There have been no confirmatory controlled trials on the therapeutic range of serum bicarbonate levels. For serum bicarbonate level to be clinically useful, in this retrospective cohort study of elderly non-dialysis-dependent CKD patients whose serum bicarbonate levels were controlled within the normal range, we evaluated the relationship between serum bicarbonate level within the normal range and CKD progression, and investigated the upper limit of the target serum bicarbonate level.

\section{Subjects and methods}

\section{Study design and study population}

This study was a retrospective cohort study of nondialysis-dependent CKD patients who were treated from 2009 to 2012 at Shiigai Clinic, Ibaraki, Japan. Patients were eligible for inclusion in the sample for this study when they were at least 60 years of age as of December 1st, 2009, diagnosed as having CKD on the basis of the criteria of the Japanese Society of Nephrology, had an estimated GFR (eGFR) of $60 \mathrm{ml} / \mathrm{min} / 1.73 \mathrm{~m}^{2}$ or lower, had never been treated by dialysis or undergone transplantation, and their serum bicarbonate levels were within the normal range (normal range, 21 to $32 \mathrm{mEq} / \mathrm{l}$ ) [18]. They usually visited the Shiigai Clinic once a month [mean interval of visit and standard deviation (SD), $33.5 \pm 3.0$ days]. Patients who were treated for dementia, lung diseases, chronic heart failure, or cancer were excluded. We treated CKD as a general practice of the clinic following the CKD practice guideline of the Japanese Society of Nephrology [18]. A high serum bicarbonate level was treated in accordance with K/DOQI guidelines 2000 [16]. Serum bicarbonate level was maintained from 22 to $32 \mathrm{mEq} / \mathrm{l}$ by administration of only sodium bicarbonate [16]. eGFR was calculated using the formula adopted by the Japanese Society of Nephrology using serum creatinine level [18]. This study was approved by the Ethics Committee of Tokyo Kyosai Hospital, Tokyo, Japan.

\section{Data}

The baseline characteristics of the population were recorded at the time of the patients' initial evaluation in the nephrology clinic. The patients' demographics including age, gender, and history of diabetes mellitus and hypertension; laboratory variables, namely, albumin, sodium, potassium, creatinine, bicarbonate, and urinary protein levels; and the use of medications, namely, renin-angiotensin-aldosterone system (RAAS) inhibitors [angiotensin- converting enzyme inhibitor (ACEI), angiotensin II receptor blockers (ARBs) or direct renin inhibitors], loop diuretics, and sodium bicarbonate were obtained from the medical records of the patients treated at the clinic. Serum creatinine level was recorded longitudinally every month. Routine serum biochemistry was carried out by standard methods at Shiigai Clinic. Serum bicarbonate level was measured by an enzymatic carbonate method using a Dimension Xpand analyzer (Siemens Healthcare Diagnostics Inc., Tokyo, Japan). We defined the outcome as a decrease of $25 \%$ or more in eGFR or starting hemodialysis or peritoneal dialysis. The observation period was two years. The patients' data were collected until they reached the outcome or changed hospital. Data from patients who changed hospitals were considered as censored observations.

\section{Statistical analyses}

Normally distributed variables are presented as mean \pm $\mathrm{SD}$; otherwise, the median and interquartile range (IQR) are presented. Intergroup comparisons were performed using the chi-square test, $t$-test, and Mann-Whitney $U$ test as appropriate. Univariate linear regression analysis and multivariate linear regression analysis were carried out to identify variables that were independently associated with serum bicarbonate level by including factors that were previously selected on the basis of $p$ level in univariate linear regression analysis ( $p$ level, 0.1 or lower). Serum bicarbonate level was defined to be low when it fell in the lower 25th percentile of serum bicarbonate level $(25.5 \mathrm{mEq} / \mathrm{l})$. Patients' survival curves were derived by Kaplan-Meier analysis. Cox proportional hazard models were used to evaluate the relationship of serum bicarbonate level with the outcome and to compare the risk of the outcome between a group with a low serum bicarbonate level (low-bicarbonate group) and the group with a normal serum bicarbonate level (control group). We adjusted several a priori-chosen covariates sequentially. Model 2 was adjusted for patient demographics, namely, age, gender, diabetes, hypertension, and body mass index (BMI); Model 3 was adjusted for variables in model 2 and laboratory variables, namely, eGFR, serum albumin, sodium, and potassium levels, and 24-hour urine protein excretion level; Model 4 was adjusted for variables in model 3 and variables for medications, namely, RAAS inhibitor use, loop diuretic use, and sodium bicarbonate use. The results are presented here as hazard ratios (HRs) with 95\% confidence interval (CI). Statistical significance was defined as $p<0.05$. These analyses were conducted using SAS, version 9.2 (SAS, Inc., Cary, North Carolina).

\section{Results}

One hundred and thirteen elderly CKD patients were included in the sample for analysis. Patient demographics 
including biochemical data are shown in Table 1. The causes of CKD were as follows: diabetic nephropathy, 38 patients, 33.6\%; chronic glomerulonephritis, 70 patients, $62.0 \%$; and others, 5 patients, $4.4 \%$. Within two years, 46 patients $(40.7 \%)$ showed a decrease of $25 \%$ in their eGFR and 10 patients $(8.9 \%)$ started dialysis. Forty six patients (40.7\%) reached the outcome, and the rate of reaching the outcome was 0.35 per patient-year. None of the patients died. Thirty-three patients changed hospital (29.2\%): lowbicarbonate group, 9 (32.1\%); control group, 24 (28.2\%).
The baseline characteristics of patients are shown in Table 1. The low-bicarbonate group and control group did not show significant differences in age, BMI, serum albumin level, sodium level, and loop diuretic use. The numbers of patients who were female, had diabetes, and had hypertension were higher in the control group. The low-bicarbonate group showed a lower eGFR, a higher potassium level, a lower bicarbonate level, a higher 24hour urinary protein excretion level, a lower number of RAAS inhibitor users, and a larger number of sodium

Table 1 Baseline characteristics of patients with low serum bicarbonate level in comparison with those of control group

\begin{tabular}{|c|c|c|c|c|}
\hline & All & Low-bicarbonate group & Control group & $p$ value \\
\hline $\mathrm{N}(\%)$ & 113 & 28 & 85 & \\
\hline Age (years) & $70.4 \pm 6.6$ & $71.0 \pm 6.9$ & $70.2 \pm 6.5$ & 0.59 \\
\hline Female (\%) & $41(36.3)$ & $5(17.9)$ & $36(42.4)$ & 0.019 \\
\hline Diabetes mellitus (\%) & $38(33.6)$ & $5(17.9)$ & $33(38.8)$ & 0.042 \\
\hline Hypertension (\%) & $45(39.8)$ & $3(10.7)$ & $42(49.4)$ & 0.0003 \\
\hline Height (cm) & $160.6 \pm 8.9$ & $164.8 \pm 8.1$ & $159.2 \pm 8.7$ & 0.005 \\
\hline Weight (kg) & $58.3 \pm 8.9$ & $60.9 \pm 9.4$ & $57.4 \pm 8.6$ & 0.08 \\
\hline $\mathrm{BMI}\left(\mathrm{kg} / \mathrm{m}^{2}\right)$ & $22.5 \pm 2.5$ & $22.3 \pm 2.2$ & $22.6 \pm 2.5$ & 0.61 \\
\hline eGFR $\left(\mathrm{ml} / \mathrm{min} / 1.73 \mathrm{~m}^{2}\right)$ & $25.7 \pm 13.6$ & $15.1 \pm 5.9$ & $29.1 \pm 13.6$ & 0.0001 \\
\hline CKD Stage (\%) & & & & 0.0001 \\
\hline 3 & $40(35.4)$ & $1(3.5)$ & $39(45.9)$ & \\
\hline 4 & $44(38.9)$ & $12(42.9)$ & $32(37.7)$ & \\
\hline 5 & $29(25.7)$ & $15(53.6)$ & $14(16.5)$ & \\
\hline Albumin level (g/dl) & $3.7 \pm 0.3$ & $3.7 \pm 0.3$ & $3.7 \pm 0.4$ & 0.99 \\
\hline Sodium level (mEq/l) & $140.7 \pm 2.3$ & $140.9 \pm 2.2$ & $140.7 \pm 2.4$ & 0.63 \\
\hline Potassium level (mEq/l) & $4.8 \pm 0.5$ & $5.0 \pm 0.5$ & $4.7 \pm 0.5$ & 0.004 \\
\hline Bicarbonate level (mEq/l) & $27.4 \pm 3.2$ & $23.4 \pm 1.8$ & $28.8 \pm 2.3$ & 0.0001 \\
\hline \multirow[t]{2}{*}{ 24-hour urine protein excretion level (g/day) } & $0.93 \pm 1.01$ & $1.25 \pm 1.19$ & $0.83 \pm 0.93$ & 0.063 \\
\hline & $0.52(\mathrm{IQR}, 0.25,1.18)$ & $1.04(\mathrm{IQR}, 0.35,1.66)$ & $0.44(\mathrm{IQR}, 0.24,1.11)$ & \\
\hline RAAS inhibitor use (\%) & $98(86.7)$ & $20(71.4)$ & $78(91.8)$ & 0.006 \\
\hline ACEI use & $51(45.1)$ & $12(42.9)$ & $39(45.9)$ & \\
\hline ARB use & $86(76.1)$ & $18(64.3)$ & $68(80.0)$ & \\
\hline Direct renin inhibitor use & $34(30.4)$ & $9(32.1)$ & $25(29.8)$ & \\
\hline Loop diuretic use (\%) & $37(32.7)$ & $11(39.3)$ & $26(30.6)$ & 0.40 \\
\hline Sodium bicarbonate use (\%) & $23(20.3)$ & $12(42.9)$ & $11(12.9)$ & 0.0006 \\
\hline \multirow[t]{2}{*}{ Dose of sodium bicarbonate (g/day) } & $0.54 \pm 1.29$ & $1.28 \pm 2.03$ & $0.28 \pm 0.78$ & 0.0006 \\
\hline & $0(I Q R, 0,0)$ & $0(I Q R, 0,2)$ & $0(I Q R, 0,0)$ & \\
\hline Decrease of $25 \%$ or more in eGFR (\%) & $46(40.7)$ & $19(67.9)$ & $27(31.8)$ & 0.0007 \\
\hline Dialysis (\%) & $10(8.9)$ & $6(21.4)$ & $4(4.7)$ & 0.007 \\
\hline Outcome (\%) & $46(40.7)$ & $19(67.9)$ & $27(31.8)$ & 0.0007 \\
\hline Follow-up days (days) & $449.3 \pm 162.7$ & $360.4 \pm 184.6$ & $478.6 \pm 144.4$ & 0.0007 \\
\hline
\end{tabular}

Values are expressed as mean \pm standard deviation. The levels of 24-hour urine protein excretion and dose of sodium bicarbonate are presented with median and IQR. The values are compared between the groups by the chi-square test, $t$-test, or Mann-Whitney $U$-test as appropriate.

Abbreviations: BMI Body mass index, eGFR Estimated glomerular filtration rate, RAAS Renin angiotensin aldosterone system, ACEI Angiotensin-converting enzyme inhibitor, ARB Angiotensin II receptor blocker, IQR Interquartile range; outcome, a decrease of $25 \%$ or higher in eGFR or starting dialysis. 
bicarbonate users than the control group. The dose of sodium bicarbonate in the low-bicarbonate group was from 0 to $9 \mathrm{~g} /$ day, and in the control group, from 0 to $4 \mathrm{~g} /$ day. The average dose of sodium bicarbonate in the low-bicarbonate group was higher than that in the control group. A larger number of patients reached the outcome in the low-bicarbonate group than in the control group. The rates of reaching the outcome in the lowbicarbonate group and control group were 0.69 and 0.24 per patient-year, respectively.

\section{Baseline serum-bicarbonate-level-associated factors}

There was a correlation between serum bicarbonate level and the levels of other markers (Table 2). Serum bicarbonate level was positively associated with gender, diabetes, hypertension, and eGFR, and negatively with potassium level, 24-hour urine protein excretion level, and sodium bicarbonate use. Multivariate linear regression analysis of the variables associated with serum bicarbonate level in the univariate linear regression analysis showed that bicarbonate level was independently associated with diabetes and eGFR.

\section{Serum bicarbonate level and CKD progression}

The Kaplan-Meier analysis showed a significant difference in the outcome among the groups (Log-rank test $p=0.0005$; Figure 1). The low-bicarbonate group was associated with a high risk of the outcome after adjustment for patient demographics, laboratory variables, and relevant medications (Table 3). A $1 \mathrm{mEq} / \mathrm{l}$ increase in serum bicarbonate level was associated with an $18.0 \%$ lower risk of the outcome (Table 3). Analysis using adjusted Cox proportional hazard models showed that this relationship was consistent; adjusted HR 0.791 [95\% confidence interval (CI), 0.684-0.914] (Table 3).

\section{Discussion}

In this study, the serum bicarbonate levels of the elderly CKD patients were controlled within the normal range. We demonstrated that a high serum bicarbonate level was associated a low risk of CKD progression in elderly CKD patients. Our findings are consistent with previous reports that a low serum bicarbonate level is associated with CKD progression [4-7,12]. There has been no study of serum bicarbonate level in elderly CKD patients. The participants in our present study were older than those in other studies [11]. This study also showed that, although the average serum bicarbonate level of the lowbicarbonate group was controlled within the normal range in accordance with K/DOQI guidelines 2000, being in the lowest quartile of serum bicarbonate levels was associated with a high risk of CKD progression. In this analysis, a low serum bicarbonate level remained independently related to a high HR of CKD progression. These findings suggest that a high serum bicarbonate level within the normal range may prevent CKD progression in elderly CKD patients.

The optimal management of acidemia or metabolic acidosis in CKD patients, including the monitoring of serum bicarbonate level and sodium bicarbonate administration, has not been established yet. Our study showed that the patients with a serum bicarbonate level lower than $25.5 \mathrm{mEq} / \mathrm{l}$ had a high risk of CKD progression. The K/DOQI guidelines 2000 and CARI guidelines

Table 2 Baseline serum bicarbonate level correlated with other factors

\begin{tabular}{|c|c|c|c|c|}
\hline & \multicolumn{2}{|l|}{ Univariate linear regression analysis } & \multicolumn{2}{|l|}{ Multiple linear regression analysis } \\
\hline & Difference in serum bicarbonate level & $p$ & Difference in serum bicarbonate level & $p$ \\
\hline Age (years) & -0.02 & 0.64 & & \\
\hline Female (\%) & 1.16 & 0.06 & 0.80 & 0.13 \\
\hline Diabetes mellitus (\%) & 1.35 & 0.03 & 1.28 & 0.033 \\
\hline Hypertension (\%) & 1.67 & 0.006 & 0.63 & 0.27 \\
\hline $\mathrm{BMI}\left(\mathrm{kg} / \mathrm{m}^{2}\right)$ & -0.045 & 0.73 & & \\
\hline eGFR & 0.13 & 0.0001 & 0.094 & 0.0001 \\
\hline Albumin level (g/dl) & 0.44 & 0.61 & & \\
\hline Sodium level (mEq/l) & 0.23 & 0.08 & 0.07 & 0.52 \\
\hline Potassium level (mEq/l) & -1.66 & 0.0045 & 0.035 & 0.95 \\
\hline 24-hour urine protein excretion level (g/day) & -0.58 & 0.049 & -0.22 & 0.40 \\
\hline RAAS inhibitor (\%) & 1.59 & 0.08 & & \\
\hline Loop diuretic use (\%) & -0.64 & 0.31 & & \\
\hline Sodium bicarbonate use (\%) & -2.70 & 0.0002 & -1.18 & 0.10 \\
\hline
\end{tabular}

Values are expressed as differences in serum bicarbonate level (estimated parameter) and $p$ values. Multiple linear regression analysis variables include gender, diabetes, hypertension, eGFR, sodium level, potassium level, 24-hour urine protein excretion level, and sodium bicarbonate use. Abbreviations: BMI Body mass index, eGFR Estimated glomerular filtration rate, RAAS Renin angiotensin aldosterone system. 


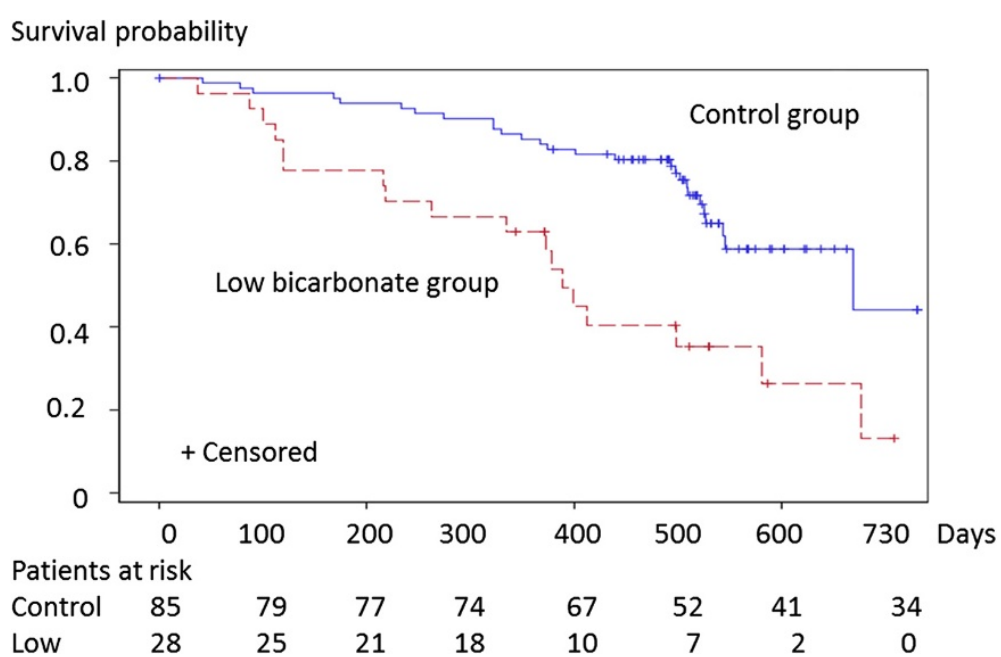

Figure 1 Kaplan-Meier analysis of CKD-progression-free-survival in low-bicarbonate group compared with control group. The numbers of patients at risk of the outcome are indicated beneath the graph. Abbreviations: CKD progression, reaching the outcome; Survival probability, probability of being CKD-progression-free.

recommend that the serum bicarbonate level should be maintained at or above $22 \mathrm{mEq} / \mathrm{l}[16,17]$. In a trial, the effect of sodium bicarbonate on CKD progression was compared between the bicarbonate-treated group and the control group [8]. The average serum bicarbonate level of the control group at baseline was $19.9 \mathrm{mEq} / \mathrm{l}$, and the average serum bicarbonate level of the bicarbonate-treated group gradually became higher than $22 \mathrm{mEq} / \mathrm{l}$ [8]. As the lower limit, $22 \mathrm{mEq} / \mathrm{l}$ may be a useful target serum bicarbonate level in clinical practice presently.

This study showed that a high serum bicarbonate level within the normal range decreased the risk of CKD progression in elderly CKD patients. A subanalysis of the African American Study of Kidney Disease and Hypertension showed that a higher baseline serum bicarbonate level within the range from 20 to $30 \mathrm{mEq} / \mathrm{l}$ was associated with a lower risk of the composite of death, dialysis, and GFR events [7]. A retrospective cohort study of the Modification of Diet in Renal Disease Study showed that patients with serum bicarbonate levels from 26 to $40 \mathrm{mEq} / \mathrm{l}$ had a lower risk of kidney failure or death than patients with serum bicarbonate levels from 11 to $25 \mathrm{mEq} / \mathrm{l}$ [6]. However, the target serum bicarbonate level in the upper limit has not been established. A cohort study showed that patients with serum bicarbonate levels higher than $32 \mathrm{mEq} / \mathrm{l}$ showed a higher risk of death than patients with serum bicarbonate levels from 23 to $32 \mathrm{mEq} / \mathrm{l}$ [12]. The effect of a high serum bicarbonate level on mortality is related to complications such as hypokalemia, hypocalcemia, or hypomagnesemia, with resultant cardiac arrhythmias [19]. These studies suggest that, as long as serum bicarbonate level is controlled within the normal range, a serum bicarbonate level higher than the lower limit may reduce the risk of CKD progression. Thus, the upper limit of the target serum bicarbonate might be equal to the upper limit of the normal range, $32 \mathrm{mEq} / \mathrm{l}$.

It has been reported that the capacity to excrete net endogenous acid decreases significantly with age [20]. Elderly CKD patients have a high risk of metabolic acidosis. It is necessary to regularly monitor their serum bicarbonate level to prevent metabolic acidosis. There has been no report about the mechanisms that definitely explain CKD progression in response to metabolic acidosis in not only elderly CKD patients but also young CKD patients. From studies using animal models, a few mechanisms are suggested. The increase in renal

Table 3 Hazard ratios for CKD progression according to baseline characteristics

\begin{tabular}{|c|c|c|c|c|}
\hline & Model 1 & Model 2 & Model 3 & Model 4 \\
\hline Serum bicarbonate level (1 mEq/l increase) & $0.820(0.735,0.915)$ & $0.816(0.720,0.924)$ & $0.811(0.700,0.940)$ & $0.791(0.684,0.914)$ \\
\hline Low-bicarbonate group (ref. control group) & $2.814(1.539,5.145)$ & $3.310(1.570,6.978)$ & $2.514(1.068,5.918)$ & $3.511(1.342,9.186)$ \\
\hline
\end{tabular}

Values are given as HRs (95\% confidence interval). Adjusted variables in four Cox proportional hazard models are as follows: Model 1 , variables in univariate Cox proportional hazard model; Model 2, adjusted for variables in model 1 and variables associated with patient demographics, namely, age, gender, diabetes, hypertension, and BMl; Model 3, adjusted for variables in model 2 and variables associated with laboratory variables, namely, eGFR, serum albumin, sodium, and potassium levels, and 24-hour urine protein excretion level; Model 4, adjusted for variables in model 3 and variables associated with the use of medications, namely, RAAS inhibitors, loop diuretics, and sodium bicarbonate.

Abbreviations: ref Reference, $B M I$ Body mass index, eGFR Estimated glomerular filtration rate, RAAS Renin angiotensin aldosterone system. 
medullary ammonia level resulting from the stimulation of ammonia production by metabolic acidosis activates the alternative complement pathway and causes progressive tubulointerstitial injury [21]. New bicarbonate synthesized by the kidney in response to acidosis alkalinizes the interstitium and promotes precipitation of calcium in the kidney [22]. Increased endothelin production may mediate the tubulointerstitial injury and decrease in GFR associated with metabolic acidosis in CKD [10,23]. The mechanism underlying the renal protective effect of sodium bicarbonate in humans has not been clarified yet, either. Studies using experimental animal models of CKD suggest that alkali therapy attenuates tubulointerstitial inflammation and may slow the progression to kidney failure [21,24]. A cohort study of the African American Study of Kidney Disease and Hypertension showed that net endogenous acid production was associated with faster CKD progression in CKD patients, whose serum bicarbonate levels were within the normal range [25]. The present study showed that a low serum bicarbonate level within the normal range was independently related to a high $\mathrm{HR}$ of CKD progression. These results suggest that a lower serum bicarbonate level might indicate a higher net production of endogenous or exogenous acids, which might be the main cause of CKD progression. The administration of sodium bicarbonate to attain an upper limit of serum bicarbonate level within the normal range may suppress CKD progression caused by net endogenous acid production, and may prevent the subsequent events such as interstitial fibrosis that lead to CKD progression.

This study has several limitations. First, as with any observational study, we were unable to compare two groups whose characteristics were controlled. The patient distribution in CKD stages was not balanced, which might have affected the results on the CKD progression in the lowbicarbonate group. Nonetheless, this study showed that serum bicarbonate level was independently associated with CKD progression after the adjustment for patient characteristics. Second, in this study, the population included patients treated and untreated with sodium bicarbonate. The proportion of sodium bicarbonate use and the dose of sodium bicarbonate were higher in the low-bicarbonate group than in the control group. The sample size was not large enough to analyze the treated and untreated patients separately. Third, in this study, we examined 113 patients. The statistical power of this study may not be sufficient for detecting the relationship between laboratory variables and CKD progression. Fourth, the number of censored observations was high. The main reason for censoring was the change of hospital. Selection and geographical biases may have been included in this study. Fifth, acidosis-related markers such as arterial blood gas, arterial $\mathrm{pH}$, and endogenous acid production were not measured. We were unable to investigate the determinants of the low serum bicarbonate levels that may contribute to CKD progression. Sixth, CKD-mineral-bone-disease-related markers, such as serum calcium, phosphate, and parathyroid hormone levels, were not measured. Therefore, we were unable to evaluate the relationship between serum bicarbonate level and bone metabolism.

\section{Conclusions}

Our data showed a possibility that a high serum bicarbonate level within the normal range may more effectively prevent CKD progression in elderly CKD patients, and suggested that the upper limit of the target serum bicarbonate level may be that of the normal range of serum bicarbonate levels. For the prevention of CKD progression, there are issues that should be resolved: when to start the treatment with sodium bicarbonate and how much sodium bicarbonate should be administered. Clinical trials using a large sample size are required to obtain strong evidence that can help guide therapies with sodium bicarbonate.

\section{Abbreviations}

CKD: Chronic kidney disease; GFR: Glomerular filtration rate; KDOQI: Kidney Disease Outcomes Quality Initiative; CARI: Care of Australians with Renal Impairment; eGFR: Estimated GFR; SD: Standard deviation; RAAS: Reninangiotensin-aldosterone system; ACEl: Angiotensin-converting enzyme inhibitor; ARBs: Angiotensin II receptor blockers; IQR: Interquartile range; Low-bicarbonate group: Group with a low serum bicarbonate level; Control group: Group with a normal serum bicarbonate level; BMI: Body mass index HR: Hazard ratios; Cl: Confidence interval.

\section{Competing interests}

No financial or other interests to be declared.

\section{Authors' contributions}

Each author contributed to this manuscript. EK and MA analyzed the data and wrote the manuscript. MA and MY contributed to the statistical analysis and interpretation of the data. RK and TS contributed to the conception and design of the study and on-going progress of the study. MA, RK and TS designed and revised this study. All authors reviewed and approved the manuscript.

\section{Author details}

'Department of Nephrology, Tokyo Kyosai Hospital, Nakameguro 2-3-8, Meguroku, Tokyo 153-8934, Japan. ${ }^{2}$ Tokyo Medical and Dental University, Bioethics Research Center, Yushima 1-5-45, Bunkyoku, Tokyo113-8519, Japan. ${ }^{3}$ Kokubunji Minamiguchi Clinic, Minamicho 3-15-6, Kokubunjishi, Tokyo 185-0021, Japan. ${ }^{4}$ Shiigai Clinic, Shinmachi 2-6-4, Torideshi, Ibaraki 302-0024, Japan.

Received: 5 August 2012 Accepted: 7 January 2013

Published: 9 January 2013

\section{References}

1. Bailey JL: Metabolic acidosis: an unrecognized cause of morbidity in the patient with chronic kidney disease. Kidney Int Suppl 2005, 96:S15-23.

2. Kraut JA, Kurtz I: Metabolic acidosis of CKD: diagnosis, clinical characteristics, and treatment. Am J Kidney Dis 2005, 45(6):978-993.

3. Kraut JA, Madias NE: Consequences and therapy of the metabolic acidosis of chronic kidney disease. Pediatr Nephrol 2011, 26(1):19-28.

4. Shah SN, Abramowitz M, Hostetter TH, Melamed ML: Serum bicarbonate levels and the progression of kidney disease: a cohort study. Am J Kidney Dis 2009, 54(2):270-277.

5. Kovesdy CP, Anderson JE, Kalantar-Zadeh K: Association of serum bicarbonate levels with mortality in patients with non-dialysisdependent CKD. Nephrol Dial Transplant 2009, 24(4):1232-1237. 
6. Menon V, Tighiouart H, Vaughn NS, Beck GJ, Kusek JW, Collins AJ, Greene T, Sarnak MJ: Serum bicarbonate and long-term outcomes in CKD. Am J Kidney Dis 2010, 56(5):907-914.

7. Raphael KL, Wei G, Baird BC, Greene T, Beddhu S: Higher serum bicarbonate levels within the normal range are associated with better survival and renal outcomes in African Americans. Kidney Int 2011, 79(3):356-362.

8. de Brito-Ashurst I, Varagunam M, Raftery MJ, Yaqoob MM: Bicarbonate supplementation slows progression of CKD and improves nutritional status. J Am Soc Nephrol 2009, 20(9):2075-2084.

9. Mahajan A, Simoni J, Sheather SJ, Broglio KR, Rajab MH, Wesson DE: Daily oral sodium bicarbonate preserves glomerular filtration rate by slowing its decline in early hypertensive nephropathy. Kidney Int 2010, 78(3):303-309.

10. Phisitkul S, Khanna A, Simoni J, Broglio K, Sheather S, Rajab MH, Wesson DE: Amelioration of metabolic acidosis in patients with low GFR reduced kidney endothelin production and kidney injury, and better preserved GFR. Kidney Int 2010, 77(7):617-623.

11. Susantitaphong P, Sewaralthahab K, Balk EM, Jaber BL, Madias NE: Shortand long-term effects of alkali therapy in chronic kidney disease: a systematic review. Am J Nephrol 2012, 35(6):540-547.

12. Navaneethan SD, Schold JD, Arrigain S, Jolly SE, Wehbe E, Raina R, Simon JF, Srinivas TR, Jain A, Schreiber MJ, et al: Serum bicarbonate and mortality in stage 3 and stage 4 chronic kidney disease. Clin J Am Soc Nephrol 2011, 6(10):2395-2402.

13. Coresh J, Wei GL, McQuillan G, Brancati FL, Levey AS, Jones C, Klag MJ: Prevalence of high blood pressure and elevated serum creatinine level in the United States: findings from the third National Health and Nutrition Examination Survey (1988-1994). Arch Intern Med 2001, 161(9):1207-1216.

14. Walker WG, Neaton JD, Cutler JA, Neuwirth R, Cohen JD: Renal function change in hypertensive members of the Multiple Risk Factor Intervention Trial Racial and treatment effects. The MRFIT Research Group. JAMA 1992, 268(21):3085-3091.

15. Bowling CB, Inker LA, Gutiérrez OM, Allman RM, Warnock DG, McClellan W, Muntner P: Age-specific associations of reduced estimated glomerular filtration rate with concurrent chronic kidney disease complications. Clin J Am Soc Nephrol 2011, 6(12):2822-2828.

16. Clinical practice guidelines for nutrition in chronic renal failure. K/DOQI, National Kidney Foundation. Am J Kidney Dis 2000, 35(6 Suppl 2):S1-140.

17. Voss D, Hodson E, Crompton C: Nutrition and growth in kidney disease: CARI guidelines. Aust Fam Physician 2007, 36(4):253-254.

18. Nephrology JS: Evidence-based practice guideline for the treatment of CKD. Clin Exp Nephrol 2009, 13(6):537-566.

19. Kovesdy CP, Regidor DL, Mehrotra R, Jing J, McAllister CJ, Greenland S, Kopple $J$, Kalantar-Zadeh K: Serum and dialysate potassium concentrations and survival in hemodialysis patients. Clin J Am Soc Nephrol 2007, 2(5):999-1007.

20. Berkemeyer S, Vormann J, Günther AL, Rylander R, Frassetto LA, Remer T: Renal net acid excretion capacity is comparable in prepubescence, adolescence, and young adulthood but falls with aging. J Am Geriatr SOC 2008, 56(8):1442-1448.

21. Nath KA, Hostetter MK, Hostetter TH: Pathophysiology of chronic tubulointerstitial disease in rats. Interactions of dietary acid load, ammonia, and complement component C3. J Clin Invest 1985, 76(2):667-675.

22. Halperin ML, Ethier JH, Kamel KS: Ammonium excretion in chronic metabolic acidosis: benefits and risks. Am J Kidney Dis 1989, 14(4):267-271.

23. Phisitkul S, Hacker C, Simoni J, Tran RM, Wesson DE: Dietary protein causes a decline in the glomerular filtration rate of the remnant kidney mediated by metabolic acidosis and endothelin receptors. Kidney Int 2008, 73(2):192-199.

24. Wesson DE, Simoni J: Acid retention during kidney failure induces endothelin and aldosterone production which lead to progressive GFR decline, a situation ameliorated by alkali diet. Kidney Int 2010, 78(11):1128-1135.

25. Scialla JJ, Appel LJ, Astor BC, Miller ER, Beddhu S, Woodward M, Parekh RS, Anderson CA, Group AASOKDaHS: Net endogenous acid production is associated with a faster decline in GFR in African Americans. Kidney Int 2012, 82(1):106-112.

doi:10.1186/1471-2369-14-4

Cite this article as: Kanda et al: High serum bicarbonate level within the normal range prevents the progression of chronic kidney disease in elderly chronic kidney disease patients. BMC Nephrology 2013 14:4.

\section{Submit your next manuscript to BioMed Central and take full advantage of:}

- Convenient online submission

- Thorough peer review

- No space constraints or color figure charges

- Immediate publication on acceptance

- Inclusion in PubMed, CAS, Scopus and Google Scholar

- Research which is freely available for redistribution

Submit your manuscript at www.biomedcentral.com/submit
( Biomed Central 